\title{
EL QHAPAQ ÑAN EN FAMATINA (LA RIOJA-ARGENTINA): RITUALIDAD Y MANIFESTACIONES SAGRADAS INKAS EN UNA WAK'A INTERREGIONAL AL SUR DEL KOLLASUYU
}

\author{
QHAPAQ NAN IN FAMATINA (LA RIOJA-ARGENTINA): RITUALITY AND \\ SACRED INKA EXPRESSIONS IN AN INTERREGIONAL WAK'A IN \\ SOUTHERN KOLLASUYU
}

Sergio Martin ${ }^{A}$

En el presente artículo discutimos la idea de considerar a la Sierra de Famatina como una wak'a de alcance interregional. Las prospecciones sistemáticas del Qhapaq Ñan sobre estos paisajes incaicos, contraponiéndose a una visión clásica eminentemente material y economicista, están redefiniendo el registro arqueológico hacia rituales religiosos evidenciados a través de la sacralización del Inka Ñan y de sus sitios asociados. Aspectos particulares de la materialidad del camino, ushnus y plataformas ceremoniales, son algunos elementos que formaron parte de las expresiones ideológicas que redefinen al Famatina como otro nuevo ámbito sagrado al sur del kollasuyu.

Palabras clave: Qhapaq Ñan, Inkas, sitios rituales, wak'a.

his article discusses the possibility of considering the Sierra de Famatina as a wak'a of interregional scope. Systematic surveys of the Qhapaq Ñan in these Inca landscapes, which contrast with extremely materialist and economistic approaches, are redefining the archaeological record in terms of religious rituals, as evidenced through the sacralization of Inka Nan and its associated sites. Particular material aspects of the road, ushnus, and ceremonial platforms are some of the ideological expressions that are redefining the Famatina as a new sacred area, in southern Kollasuyu.

Keywords: Qhapaq Ñan, Inkas, ritual sites, wak'a.

\section{INTRODUCCIÓN}

La sierra de Famatina ubicada al noroeste de la Provincia de La Rioja (fig. 1), ha sido destacada reiteradamente en la historia regional como una zona de alta relevancia económica para el gobierno inka. La visión economicista de esta formación geológica como un yacimiento de importantes riquezas minerales ha sido, además, advertida en algunas crónicas conocidas y en varios de los trabajos arqueológicos publicados al respecto, atribuyéndole incluso un importante poder político como área de posible asentamiento de curacazgo de la provincia austral, desde la que se impartían y controlaban los territorios más meridionales de Argentina y Chile (González 1982). Sin embargo, la aplicación de un sistema de prospecciones intensivas del Qhapaq Nan y la integración del contexto arqueológico de sus paisajes están redefiniendo un ámbito con tendencias más afines a la explotación del Famatina como un espacio ceremonial y validando, de acuerdo a nuestras interpretaciones, un registro arqueológico vinculado mayormente a aspectos rituales o sagrados, evidenciados a través de la sacralización de los caminos (Martin 2015a, 2015b) y de varios

\footnotetext{
A Sergio Martin, Instituto Nacional de Antropología y Pensamiento Latinoamericano (INAPL), Ministerio de Cultura, Buenos Aires, email: smartinarque@gmail.com
} 
de sus sitios asociados (Schobinger 1966; Ceruti 2007, 2010). Las características formales de sus caminos y los emplazamientos de ushnus y plataformas ceremoniales, detectadas y relevadas sobre el Qhapaq Ñan en la variada geografía de la sierra, forman parte de las expresiones materiales a las que nos referiremos al proponerla como otro espacio sagrado del área andina sur.

A continuación, ofrecemos datos que pueden ayudar a definir y determinar si el concepto wak'a, se adecúa a las evidencias arqueológicas de este sector. Luego describiremos la transformación que se produce desde la sesgada visión economicista de las crónicas, fundada en la historia minera, hasta la visión de un espacio que estaría demostrando el interés del incario por la Sierra de Famatina en su rol de waka.

\section{HACIA LA DEFINICIÓN DEL CONCEPTO WAK'A}

Los paisajes del oeste sudamericano han incidido activamente en la ideología religiosa de sus pobladores. Incluso en la actualidad los pueblos andinos consideran que algunos accidentes geográficos son sagrados y deben ser venerados para recibir como contraparte protección hacia las personas y el mundo natural (Sallnow 1987: 2; Fernández \& Gutiérrez 2012: 19; Reinhard 2012: 68). Los cultos y rituales se desarrollan en lugares donde las comunidades describen las percepciones de los paisajes naturales en los que se insertan en función de sus cosmovisiones (Becerril 2012: 69). Se trata de espacios activos y muy dinámicos con características bien marcadas y cambiantes que se transformaron a lo largo del tiempo y que hoy definimos como paisajes rituales (Broda 1996: 42); ámbitos de peregrinajes y procesiones por geografías cargadas de significados naturales y culturales (Vitry 2007: 70) que fueron recogidas por los cronistas, mostrando que en América los movimientos rituales de personas también existían (Rostworowski 2003: 98). Los sitios sagrados que ocupaban estos ámbitos en el mundo andino han recibido el nombre de guacas, huacas o wak'as y han sido identificados y caracterizados fundamentalmente por los documentos etnohistóricos en los movimientos de extirpaciones idolátricas que las describían y por sitios arqueológicos de adoratorios, santuarios y caminos prehispánicos que han sido detectados y estudiados en varios puntos de la geografía andina.
El término wak'a fue utilizado para designar cualquier cosa o lugar que tuviera poderes trascendentes (D’Altroy 2003: 174). Podía ser un accidente natural, agua, manantiales, rocas, árboles, cuevas, montañas, frutos o cualquier otro tipo de objetos. Esta heterogeneidad de formas, materiales, tamaños y jerarquías agregaba un margen de flexibilidad para que el Inka incorporara con las wak'as fijas a las poblaciones locales bajo estructuras de creencias similares, mientras que con las wak'as móviles trasladará aspectos ideológicos a lugares y/o poblaciones más distantes (Scott 2011: 23-24).

Aunque fueron más conocidas durante la época inka, las wak'as han estado presente en la vida cotidiana de las poblaciones andinas mucho antes de la aparición del incario. Sus orígenes han sido establecidos desde épocas anteriores a la formación del imperio del Tawantinsuyu en las religiones de las poblaciones locales (D'Altroy 2003: 175; Rostworowski 2004: 27; Sánchez Garrafa 2006: 52; Cruz 2009: 58; Bauer 2011: 58-61; Scott 2011: 23).

El poder de su convocatoria pudo involucrar cultos locales de tipo familiar, poblaciones de varias regiones o grandes centros que captaban la concurrencia de personas de lejanas procedencias y de nivel panandino (Bauer 2011:30). También sirvieron para varios motivos, entre ellos para desarrollar la complementariedad de recursos, como estrategias de alianzas y/o generando lazos de reciprocidad al recibir peregrinos de regiones distantes, que en su afán participativo permitían contribuir al desarrollo de las comunidades gracias al espíritu concitante de las wak'as (Rostworowski 2004: 26-27).

\section{Los cerros y montañas wak’a}

Las sierras y las montañas wak'a fueron importantes en el desarrollo de la historia social precolombina. Una montaña, como cualquier marca visual que se percibe desde el horizonte, se torna esencial y adopta o adquiere un valor simbólico particular (Claval 1999: 164). Reconociendo que también se han erigido wak'as en cerros de escasa altura (Bárcena 1989: 104; Cruz 2009: 56; Jacob \& Leibowicz 2011: 75), las formaciones montañosas de relieves topográficos imponentes, con cotas altitudinales importantes, combinaron diversos aspectos de la materialidad e inmaterialidad de las comunidades prehispánicas (Vitry 2007: 82-83). Las montañas fueron incorporadas por las culturas andinas como hitos o referencias para guiarse territorialmente; como moradas de apus; mediadoras entre el mundo sobrenatural y el 


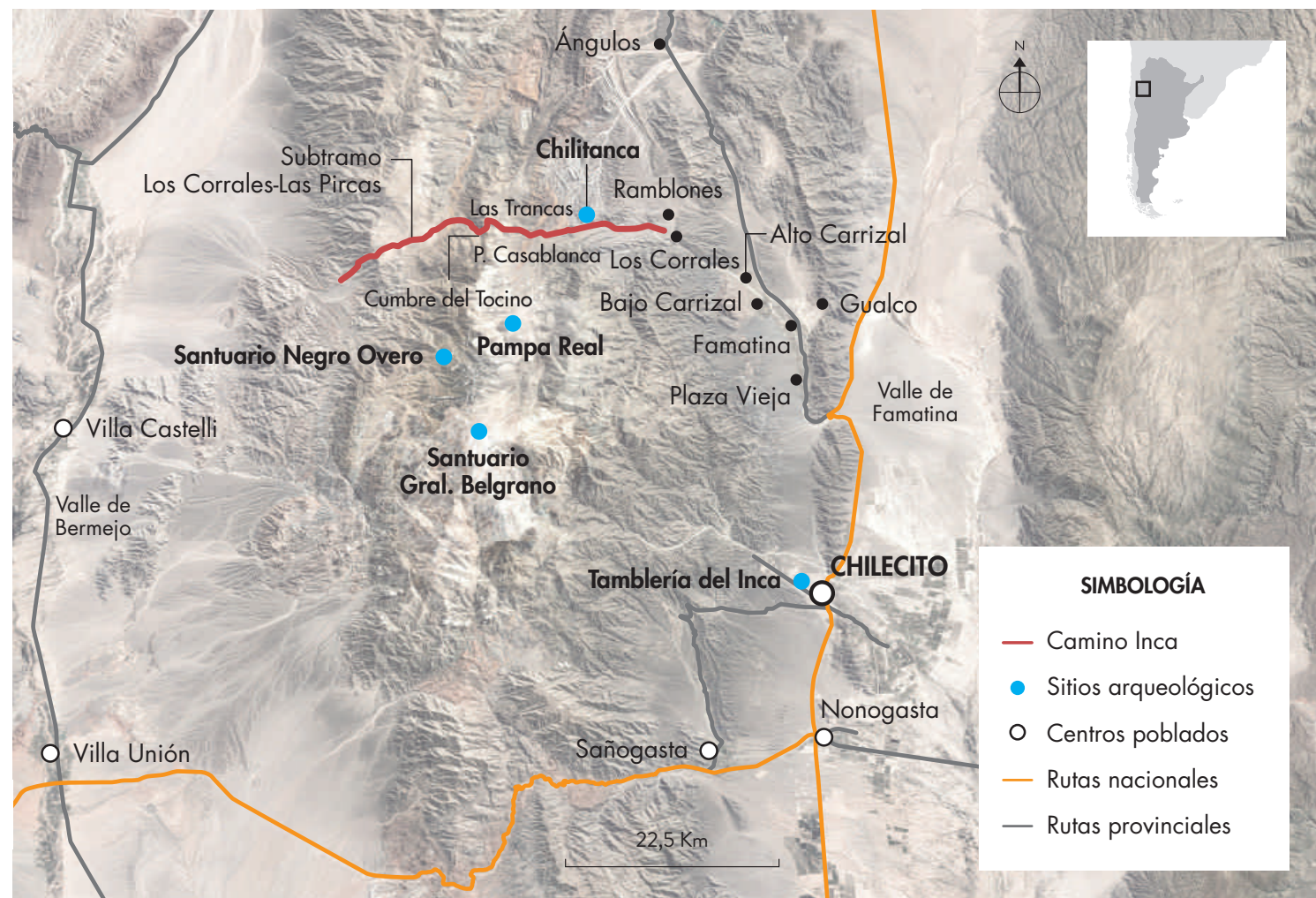

Figura 1. Área de la sierra de Famatina y sitios del contexto incaico regional. Figure 1. Area of the Famatina mountain range and surrounding Inca sites.

terrenal; como elementos dinamizantes de movimientos rituales de personas (procesiones y peregrinajes); como factor de cohesión entre las creencias y deidades de las poblaciones que habitaban la región circundante y, fundamentalmente, como un instrumento para establecer el control político y hegemónico de territorios que cubrieran sus proyectos expansivos. Creemos que esto sucedió con la sierra de Famatina, una de las serranías más emblemáticas en la historia social, económica y política del noroeste argentino.

Con la intención de demostrar la visión que ha tenido esta formación en los estudios de la arqueología inka, resumiremos desde un marco histórico y regional, el surgimiento de esta formación como un lugar percibido y reconocido. Para ello nos valemos de menciones en documentos de épocas fundacionales, crónicas provenientes de viajeros, geólogos y naturalistas que, durante el siglo xIx y Xx, registran datos de interés para nuestra disciplina, además de un breve comentario de los principales antecedentes de investigaciones arqueológicas relacionadas con la dominación imperial.
Estas menciones dirigen principalmente sus objetivos y miradas a la sierra de Famatina como área neurálgica de explotaciones mineras por parte de los inkas.

\section{El Famatina y su lugar en la historia del Noroeste Argentino}

Algunos historiadores mencionan que alrededor de cuarenta años antes de la fundación de la capital provincial de La Rioja, el territorio provincial fue visitado por García de Almadén, Francisco de Mendoza, Núñez de Prado y Francisco de Aguirre (De La Fuente 1969: 19). De estos adelantados, Núñez de Prado fue el primero de los europeos que, en diciembre de 1552 o en los primeros meses de 1553, recorrió la zona de Famatina e insertó a la región como una de las más promisorias e influyentes del Tucumán colonial. A partir de esta fecha, Famatina cobra significado como lugar y es mencionado por algunos cronistas. Tal es el caso del oidor de la Audiencia de Charcas, el licenciado Juan Matienzo que, en una carta enviada a Felipe II el 2 de enero de 1556, 
vincula a Famatina como parte de los caminos del Perú: "De salta a Agualasto hay veinticinco leguas, allí están las minas ricas del Inga, a donde ha de poblarse otro pueblo. De Agualasto a Famatina treinta y cinco leguas, a donde debe estar otro pueblo que sería muy rico, y de allí a Curunera, otras setenta leguas: queda la ciudad de Santiago en triangulo entre Famatina y Curunera" (Matienzo 1910 [1567]: cap. xv. p. 275).

Las menciones de Matienzo respecto del Famatina para algunos historiadores señalan la intención de fundar ciudades en lugares relevantes desde el punto de vista económico y con poblaciones importantes en función de la mano de obra indígena (De la Fuente 1969: 29). Incluso esta habría sido la intención del fundador de La Rioja, Ramírez de Velasco en 1591, aunque se discute si confunde la sierra de Velasco con la de Famatina, tal como sugiere el historiador Félix Luna (Bazán 1979: 8), o si existió un accionar premeditado entre Ramírez de Velasco y el financista de la expedición Blas Ponce, para fundar una ciudad próxima a la región del Famatina. Esto habría permitido asegurar esta zona potencialmente minera del avance de la Capitanía General de Chile que ya estaba enviando generales y encomenderos a la región de Valle Fértil (Provincia de San Juan), con la consecuente posibilidad de apoderarse de las minas del Famatina (Robledo 2007: 156-157). En cualquiera de los casos existía un factor común que era la Sierra de Famatina, que Velasco conocía (Levillier 1920), y un interés particular por su importancia económica basada en sus mentadas y "fabulosas" riquezas minerales, tal como manifiesta el primer cronista de La Rioja, el escribano Luis de Hoyos, sobre la gesta colonizadora desde la ciudad de La Rioja a este cordón serrano:

su señoría del señor gobernador se determino de yr en persona a la rrehdificación de la dicha ciudad de todos los santos de la nueva rioja que había dejado poblada y a conquistar e allanar los yndios que no obiesen dado la paz o al descubrimiento de la gran noticia que auia de que en los cerros llamado famatina que caen en la jurisdicción que se dio a la dicha ciudad avia mucha cantidad de minerales de plata e que se labraban en tiempo del ynga e ansi mesmo que avia minas de oro e açogue (Levillier 1926, tomo II: 505).

En la misma línea se ubica la documentación que pocos días después del hallazgo de socavones indígenas, en cartas enviadas al Rey de España en abril de 1592, comenta la opulencia y riquezas del cerro que, a decir del gobernador, superaban incluso al mismo Potosí, valorizando y acrecentando aún más la fama del cerro: " $y$ mediante la voluntad de dios pienso descubrir grandes minerales porque la tierra da muestra dellos y hazer a su majestad vno de los señalados seruicios que se ayan hecho en nuestros tiempos y que el nombre de famatina quede formado en fama en tiempo de vuestra señoría ilustrísima" (Levillier 1926, tomo I: 305-306).

Relacionado a la riqueza minera, en casi todas las menciones de las crónicas, el Qhapaq Ñan es el denominador común que aparece reflejando la presencia inka. Esto se puede apreciar en el paso de Diego de Almagro en 1535 por la cordillera riojana (Raffino 1996), en las expediciones de Núñez de Prado cerca de la localidad de Famatina (Carrizo 1942: 41) y en las menciones explícitas del fundador de La Rioja. Este último, en 1587, luego de incursionar por cincuenta días en los valles Calchaquíes tomó conocimiento de la ubicación de minas de oro y plata en Famatina, y en una carta escrita al rey mencionó la existencia de la vialidad inka: "procurare traer a servidumbre los indios de Omaguaca, Casavindo y Calchaquí y pienso poblar una ciudad entre Chile y Famatina de manera que se pueda ir con mucha brevedad de Potosí a Chile por el viejo camino del inga" (Levilier 1920: 244).

Respecto a los sitios arqueológicos de épocas incaicas vinculados a la minería, son estos de rara mención. Quizás la más importante excepción es una cita de Lozano, quien se refiere al Famatina y a las instalaciones de la Tambería del Inca en Chilecito:

\footnotetext{
donde descubrieron su opulento cerro, que según la fama tiene todas sus entrañas penetradas de riquísimas vetas de plata, las que beneficiaron los incas, y por esta razón conservaron con gran empeño este sitio; poniendo en él una numerosa guarnición para defenderle de las hostilidades e invasiones de los comarcanos, y aun asegurarle con este presidio de alguna solevación de los naturales ya rendidos, y dicen reconocen vestigios de la fortaleza, que quieren fuesen de los Ingas (Lozano 1874 [1740-1745]: 6).
}

Son varios los investigadores que, haciéndose eco de lo plasmado por los documentos históricos y en percepciones propias de visitas a terreno, recorren pequeños segmentos del Qhapaq Ñan en las serranías del Famatina y/o describen algunos de los sitios inkas asociados a la red vial (Uhle 1912; Debenedetti 1917; Boman 1920; Aparicio 1936; Rhomeder 1949; Schobinger 1966; De la Fuente 1971; González 1982; Raffino 1982; Ceruti 2007, 2010; Bárcena \& Martin 2009; Martin 2005, 2015a, 2015b; entre otros). 
Boman (1920), Kuhn (1919) y Rhomeder (1949), han considerado que las poblaciones en los sitios de alta montaña cumplieron la función de moradas de mineros prehispánicos que explotaron minerales en las partes más altas de la Sierra. También Schobinger (1966) y Ceruti (2007), luego de los descubrimientos de los santuarios de altura en las cumbres del Negro Overo y General Belgrano, sugieren una comunión entre las actividades mineras y las ceremonias rituales ubicadas en los sitios de altura.

La construcción de esta tradición minera incaica estuvo fundada en las menciones precedentes y en otros trabajos arqueológicos regionales (Raffino 1982), en la presencia de la traza de la red vial del imperio que circula por sus paisajes y en la existencia de sitios de singular importancia arquitectónica, emplazados en las cercanías de este afloramiento (Greslebin 1940; González 1982).

Aun cuando en nuestras primeras aproximaciones al área de estudio consideramos atractiva la idea de la "formación minera" y exploramos algunos aspectos en este sentido (Martin 2001, 2004) hasta el presente, nuestras expectativas respecto del registro minero inka ha sido negativo.

Transitivamente, asignábamos estas condiciones también al Qhapaq Nan e incluso, imbuidos de todas las menciones del potencial minero de la región (Raffino 1982), creíamos que el camino incaico que atravesaba el Famatina lo hacía principalmente en función de objetivos económicos como la minería (Martín 2001). Sin embargo, la aproximación al terreno mostraba que los caminos conformaron en esta región un disperso conjunto de datos, con informaciones parciales que transformaban este accidente geográfico en un verdadero "nudo" vial y requerían aproximaciones que integraran las referencias anteriores con los resultados obtenidos en la actualidad (Bárcena \& Martin 2009). En definitiva, más que un contexto orientado a la explotación minera, se detectó un sistema vial con particularidades propias que, desde lo arqueológico, tiende a resignificar los espacios de la sierra de Famatina, utilizando caminos ceremoniales y estructuras arquitectónicas orientadas hacia rituales religiosos.

\section{CAMINOS, USHNUS Y PLATAFORMAS: ESTRUCTURAS ESTATALES PARA LA DOMINACIÓN DE ESPACIOS RITUALES EN LA SIERRA DE FAMATINA}

Por una cuestión de espacio no abundaremos aquí en datos relacionados con las tipologías del Qhapaq Nan. Solamente señalaremos que existen aspectos cualitativos y cuantitativos que han sido tratados en otra oportunidad (ver Martin 2015a, 2015b); tipologías y contextos de los caminos que son únicas en la provincia de La Rioja o incluso en el área de influencia inka del noroeste (NOA) y centro oeste argentino (COA). Nos referimos principalmente a los caminos dobles, duales y/o paralelos (fig. 2), que ascienden las laderas del cerro y que, asociados a una serie de estructuras rituales menores como las wankas y mojones (fig. 3), demarcan los límites de ingreso a los espacios sagrados del Famatina (Martin 2015a: 93). En tal sentido, hemos interpretado también que los caminos duales ubicados en la pampa de Casablanca constituyen el último lugar con relieve más regular como para materializar estas asociaciones de wankas y mojones con distribuciones lineales y extensas sobre el paisaje. Incluso esta conjunción entre los sitios menores y los caminos dobles como marcadores de espacialidad podrían vincularse con aspectos agriculturales. El sector más alto de esta geoforma (entre los 2900 y $3000 \mathrm{msnm}$ ), próximo al sitio donde están ubicados los mojones y las wankas, delimita efectivamente la frontera fitogeográfica y ambiental que separa las provincias del Monte y Puneña y con ello las áreas más favorables de prácticas agrícolas tradicionales (Martín 2015a). Estas observaciones, que pueden incluir factores topográficos, ambientales y visuales nos parecen relevantes, si consideramos que, desde una perspectiva cosmológica andina, los límites transicionales denominados punkus reconocen que la culminación de un espacio y el inicio de otro deben ser venerados y recibir ofrendas (Vitry 2002: 11; Sanhueza 2011: 333). Además, los antecedentes de algunos espacios del Tawantinsuyo han demostrado que los inkas en las entradas y salidas a los ámbitos rituales monumentalizan algunos sectores del entorno físico con el objeto de visibilizar la condición ceremonial de estas áreas (Hyslop 1992). En resumen, las rutas de ascenso hacia las áreas ceremoniales de los adoratorios de altura validan desde el piedemonte oriental y occidental un escenario destinado al desarrollo de actividades sim- 


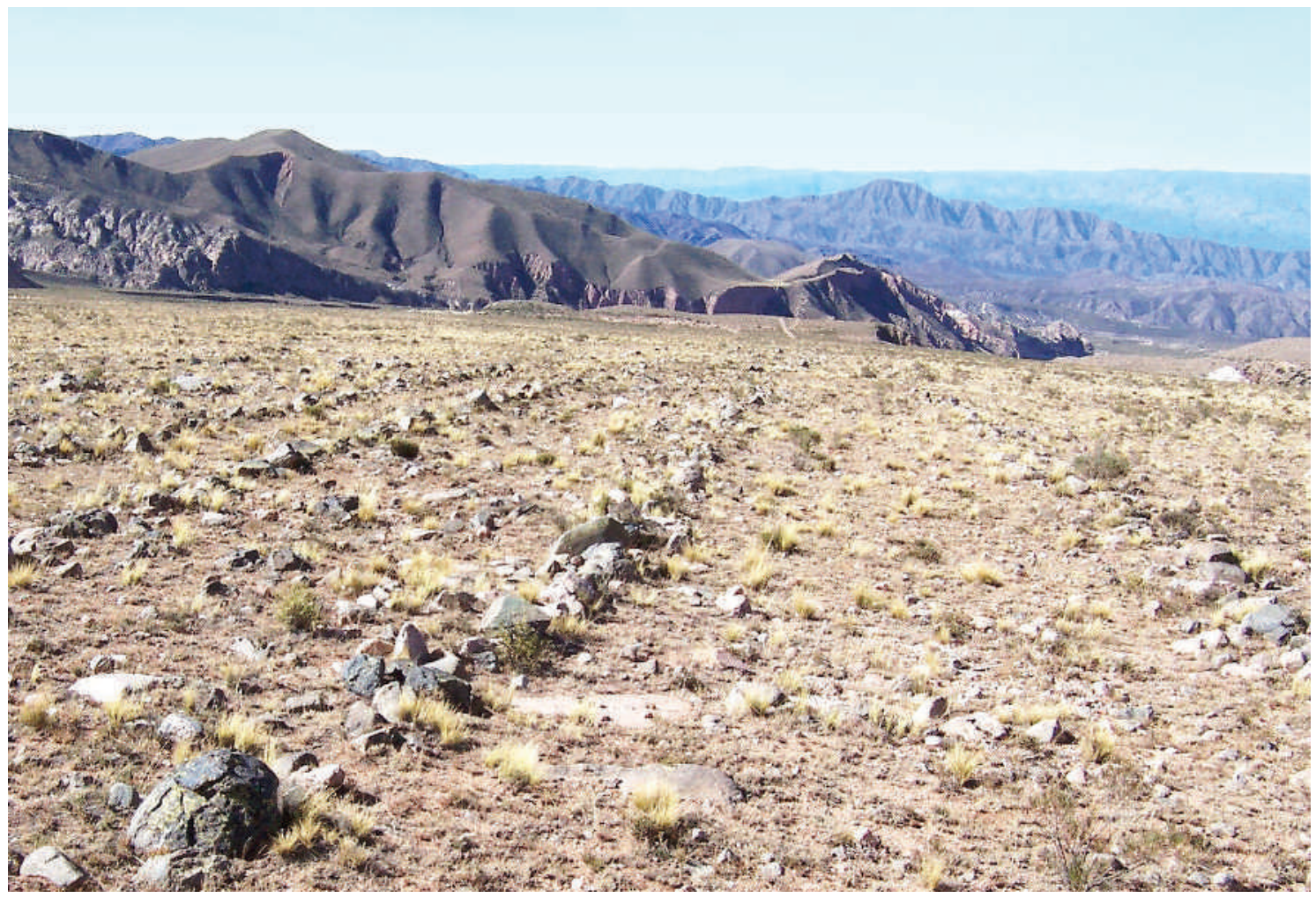

Figura 2. Caminos ceremoniales dobles, duales y/o paralelos en la pampa de Casablanca y próximos al sitio Chilitanca, en la ladera oriental de la sierra de Famatina. Figure 2. Double, dual and/or parallel ceremonial paths in the pampa of Casablanca near the Chilitanca site, on the eastern slope of the Famatina mountain range.

bólicas y demarcan los límites de ingreso a los espacios sagrados de esta sierra (Martin 2015a: 93).

Junto a estos estos componentes espaciales del Qhapaq Nan, existen otras estructuras que lograron fusionar aspectos de la arquitectura inka y el paisaje (Vitry 2007: 70; Jacob \& Leibowicz 2011: 74) para establecer mecanismos de dominación ideológica en las áreas que se quisieron conquistar (Farrington 1992: 370; Pino 2004: 303). Estas estructuras a las que nos referiremos son precisamente los ushnus y las plataformas ceremoniales detectadas en las laderas y cumbres de la sierra de Famatina.

\section{El Ushnu de Tambería del Inca}

Todas las apreciaciones coinciden en que los ushnus eran las estructuras de carácter ceremonial más relevantes del incario, estrechamente relacionadas al funcionamiento político, administrativo y religioso del ordenamiento del imperio (Meddens et. al 2010: 174). En un plano muy general, los ushnus fueron indispensables para establecer la conexión entre las wak̉as y las áreas que los inkas conquistaban (Pino 2010a: 56; Pino \& Montalván 2014: 79). Basándose en este último aspecto, existen incluso interpretaciones más específicas sobre la cosmología inka en que se concibe a los ushnus como el centro del mundo inka; un espacio sagrado desde el que se podían establecer las conexiones con el Ukhu Pacha o mundo de abajo y el Hanan Pacha o mundo de arriba (Farrington 2016).

En los últimos 30 años se han intensificado los estudios de las plataformas ushnus y están ocupando un lugar relevante en el desarrollo de las investigaciones sobre el mundo inka, con relevamientos y excavaciones tanto en el área peruana (Zuidema 1980; Matos 1994; Meddens 1997; Pino 2004, 2010a; Meddens et. al 2010; Monterverde 2011; entre otros), como en la región más meridional del Kollasuyu (Raffino et. al 1997; Lynch et al. 2010; Jacob \& Leibowicz 2011; entre otros). ${ }^{1}$ 

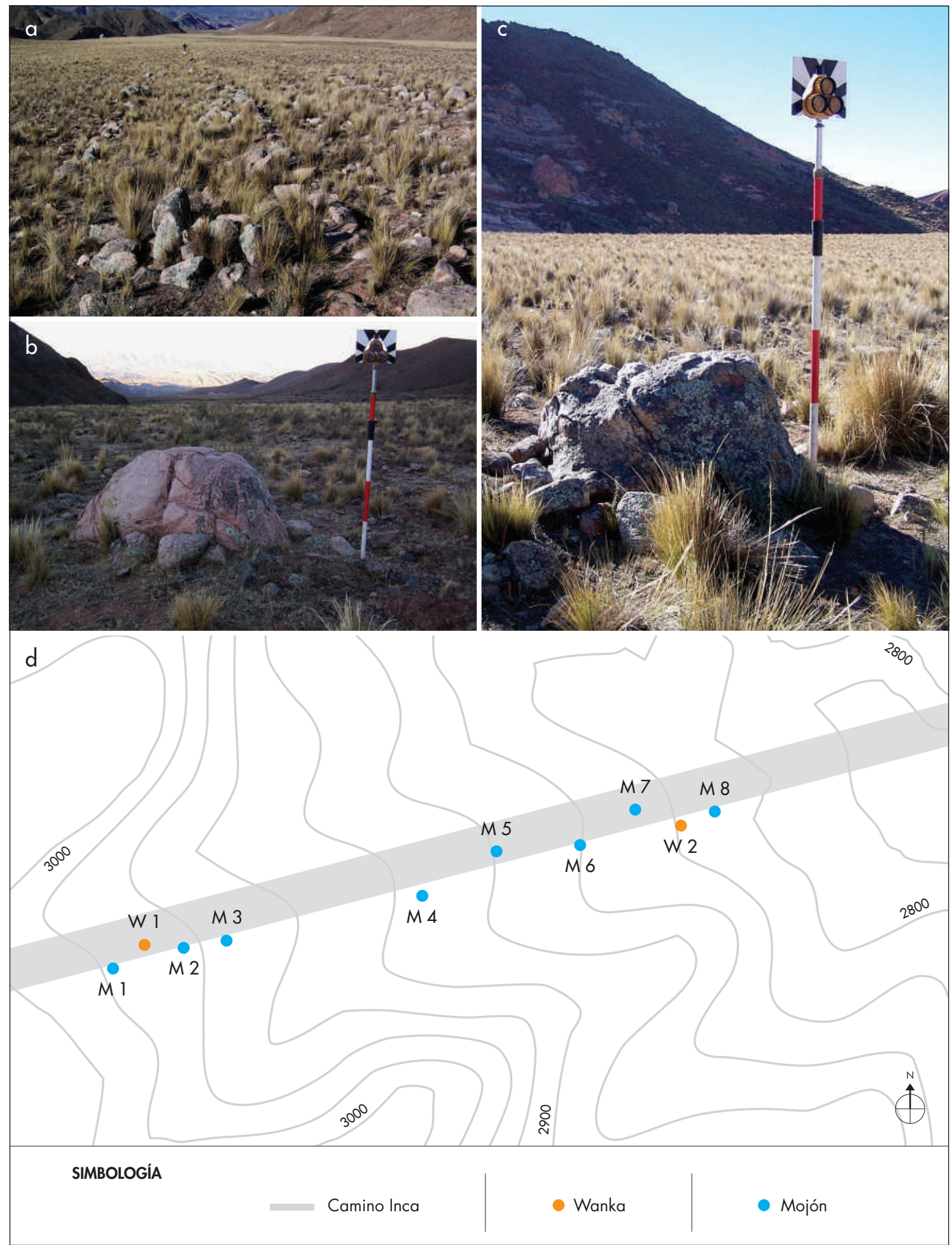

Figura 3: a) mojón entre caminos dobles; $\mathbf{b}$ ) wanka $\mathrm{N}^{\circ} 2 ; \mathbf{c}$ ) wanka $\mathrm{N}^{\circ} 1 ; \mathbf{d}$ ) registro espacial de sitios menores (wankas y mojones) en la pampa de Casablanca, ladera oriental de la sierra de Famatina. Figure 3: a) cairns between double paths; b) wanka $N^{\circ} 2 ; \boldsymbol{c}$ ) wanka $N^{\circ} 1$; d) spatial registration of smaller sites (wankas and cairns) in Casablanca pampa, eastern slope of the Famatina mountain range. 
Las tareas arqueológicas permitieron descubrir que existe una importante variabilidad de formas, tamaños y ubicaciones de los ushnus en distintos ámbitos del vasto territorio del imperio (Oberti 1997: 7; Jofré 2015: 8), por lo que aún se discute sobre sus formas, la composición de sus partes y lo que cada uno de ellos pudo haber representado (Pino 2010a: 46). Esta apertura investigativa está generando propuestas de reevaluaciones de este concepto (Farrington 2016) ya que, utilizando las rígidas categorías de la información etnohistórica, muchos de los nuevos registros de ushnus detectados, quedarían excluidos definitivamente de esta jerarquía.

Se ha podido comprobar que los ushnus no solo están en plazas y sitios importantes arquitectónicamente, sino también en los caminos o alejados de los grandes centros poblados, emplazados a diferentes altitudes; pueden tener arquitectura o ser simplemente receptores de ofrendas (ver Farrington 2016); estar compuestos por varias plataformas superpuestas o simplemente sobreelevadas en un mismo plano sobre el suelo. Su sistema constructivo puede incluir cantería fina, rústica o estar formado solamente por una roca delimitada por otras a su alrededor (Tarragó \& González 2004), entre algunos de sus aspectos constitutivos más relevantes.

En la sierra de Famatina el único ushnu reconocido arqueológicamente para la ladera oriental, es el que toma como centro arquitectónico el sitio Tambería del Inca (González 1980; Raffino 1982), ubicado al pie de la serranía en plena urbe de la actual ciudad de Chilecito, a 1189 msnm, considerado el bastión del imperio peruano más relevante en el actual territorio de la Provincia de La Rioja. Sus instalaciones están inscriptas en una forma más o menos circular de más de 16 hectáreas, que recuerdan el sistema ceque del Cuzco (Zuidema 1995) con un patrón de construcciones dispersas, planificadas en las inmediaciones de un muro de forma trapezoidal de 1,70 $\mathrm{m}$ de altura que los rodeaba en toda su extensión y que imponía una verdadera arquitectura de poder (fig. 4).

Este sitio ha tenido diversas consideraciones funcionales en el transcurso de las investigaciones arqueológicas como un campo fortificado con represa y lugares para cultivos (Debenedetti 1917: 391); una fortaleza amurallada (Uhle 1912: 65); una instalación que controlaba y resguardaba la riquezas naturales del cerro Famatina (De la fuente 1977: 8 ); un centro administrativo ordenando el espacio hacia el sur durante el proceso de expansión inka (Raffino 1982: 261 ); y una huamani o capital inka que lo convertía en el centro administrativo más austral del Tawantinsuyu con intereses orientados hacia el desarrollo minero metalurgista (González 1982: 323).

El ushnu de Tambería del Inca (el más austral conocido para la dominación peruana en Argentina) está compuesto por una plataforma de tierra sobreelevada recubierta por muros asentados con barro y siguiendo a Greslebin (1940:101) presenta una planta rectangular de $9,80 \times 16 \mathrm{~m}$ con una altura calculada en $1,60 \mathrm{~m}$ aproximadamente. ${ }^{2}$ Hacia el sur de la plataforma y adosada internamente sobre el muro oriental supo tener una estructura rectangular de $2,80 \mathrm{~m} \mathrm{x} 8,50 \mathrm{~m}$, con una división central donde probablemente se produjeron las libaciones y depositación de ofrendas. Hacia el este presenta una escalinata adosada en la parte central del muro con un ancho de 2,50 m. en la que identificamos que tuvo al menos 11 peldaños (fig. 5).

La orientación de esta construcción sigue aproximadamente las líneas de los puntos cardinales con la escalinata hacia el este y el frente del ushnu al oeste, a unos $340^{\circ}$ de azimut (de norte a este) enfrentada a la cumbre del Famatina y sus dos nevados, cerros General Belgrano y Negro Overo.

El ushnu no ha tenido intervenciones de excavaciones profesionales. Greslebin realiza una excavación muy expeditiva y menciona el hallazgo de débiles capas de ceniza, una conana ${ }^{3}$ y dos manos que adscribe a ocupaciones previas al funcionamiento de la Tambería (Greslebin 1940: 106).

También se detectó una conana y estructuras de combustión en torno a la plataforma y entre los diez años que tarda Greslebin en volver a visitar Tambería (1928-1938) se produce una importante destrucción del mismo. ${ }^{4}$

\section{Plataformas y rectángulos ceremoniales en caminos y cumbres del sistema del Famatina}

Las prospecciones en áreas de altura realizadas en las últimas décadas han permitido identificar un interesante registro de estructuras sagradas inkas en lugares alejados de los centros más densamente poblados erigidos por el estado peruano. La aparición de los "ushnus aislados" en regiones de la puna peruana de Ayacucho (Cavero 2010; Jofré 2015) aportan sin duda las bases para dirigir una mirada más profunda a este tipo de registro en otras áreas de dominación del imperio. En en el mismo 


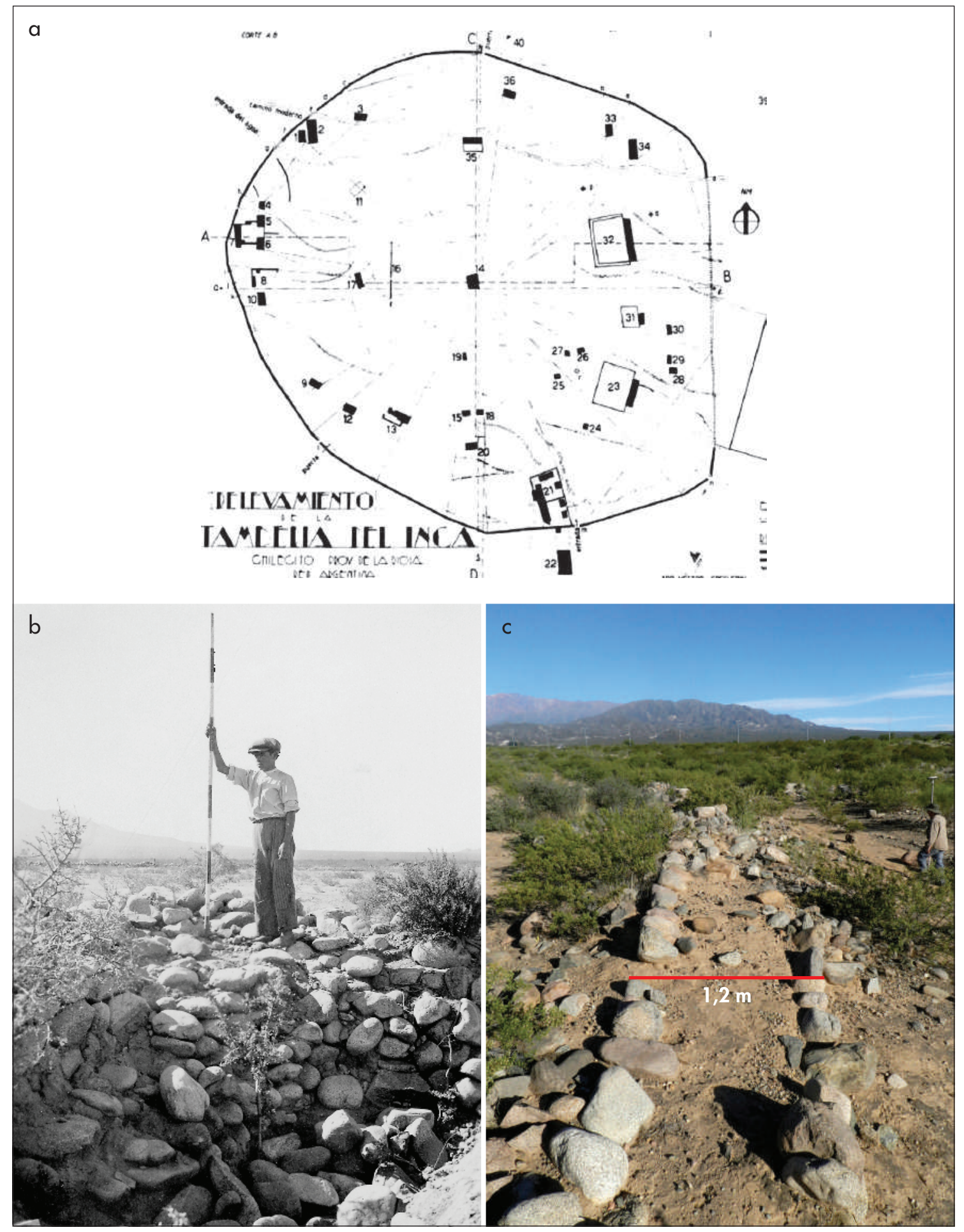

Figura 4: a) plano de Tambería del Inca según Greslebin (1940); b) detalles de estructuras arquitectónicas en las fotografías de Greslebin (1940); c) foto del muro perimetral que muestra la arquitectura "de poder" del inka en Famatina. Figure 4: a) map of the site of Tambería del Inca according to Greslebin (1940); b) details of architectural structures in Greslebin's photographs (1940); c) photo of the perimeter wall depicting an example of Inka "power" architecture in Famatina. 

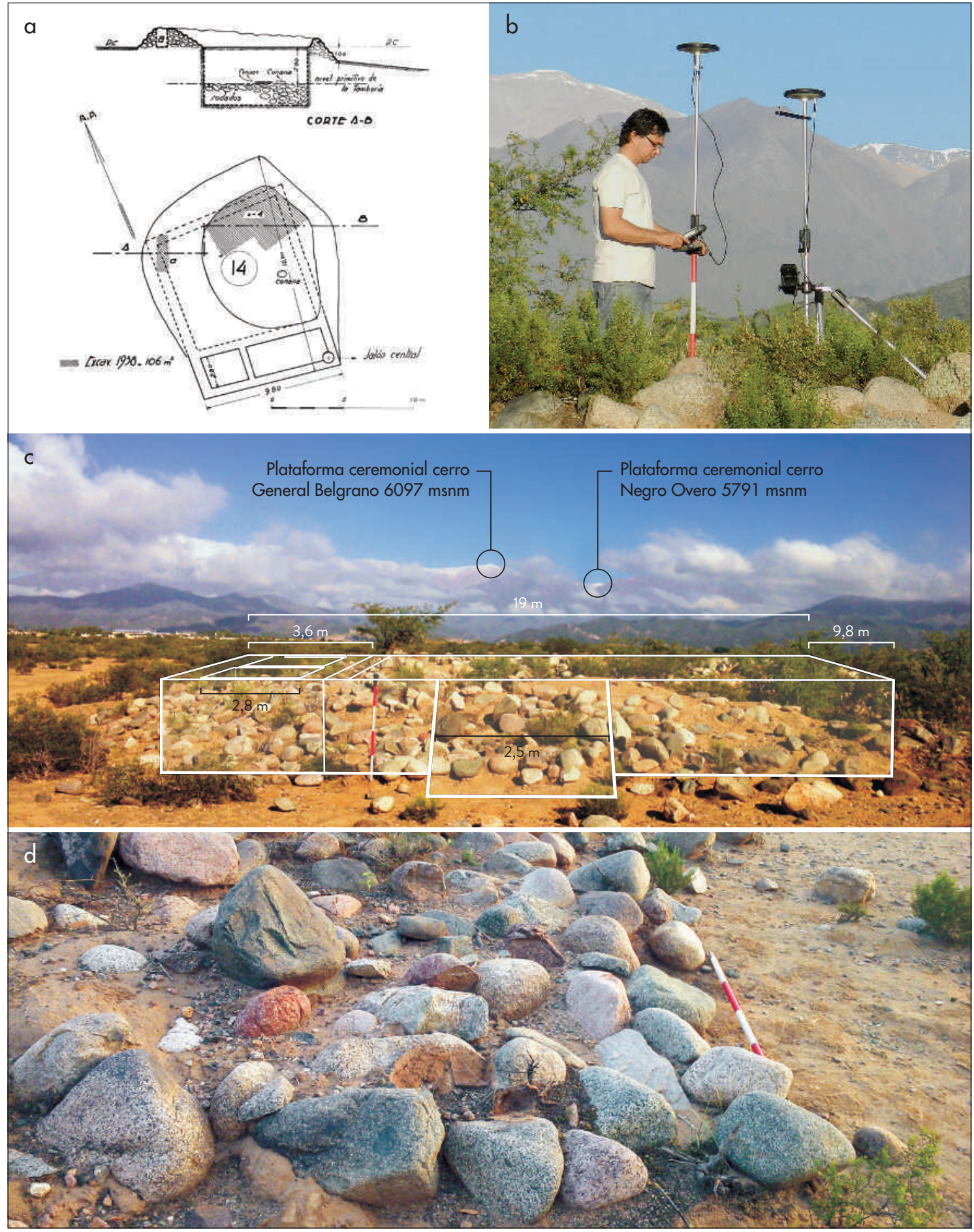

Figura 5: a) plano del ushnu de Tambería del Inca según Greslebin (1940); b) tareas de relevamientos con GPS Geodésico en el ushnu; c) reconstrucción hipotética virtual de la estructura del ushnu y estado actual de la misma; d) detalle de la escalinata que permite el ascenso de frente a los nevados de la Sierra de Famatina. Figure 5: a) plan of the ushnu of Tambería del Inca according to Greslebin (1940); b) surveys with Geodesic GPS in the ushnu; c) virtual, hypothetical reconstruction of the ushnu structure and its current condition; d) detail of the stairway that allowed people to ascend the platform while facing the snowcapped summits of of Sierra de Famatina. 


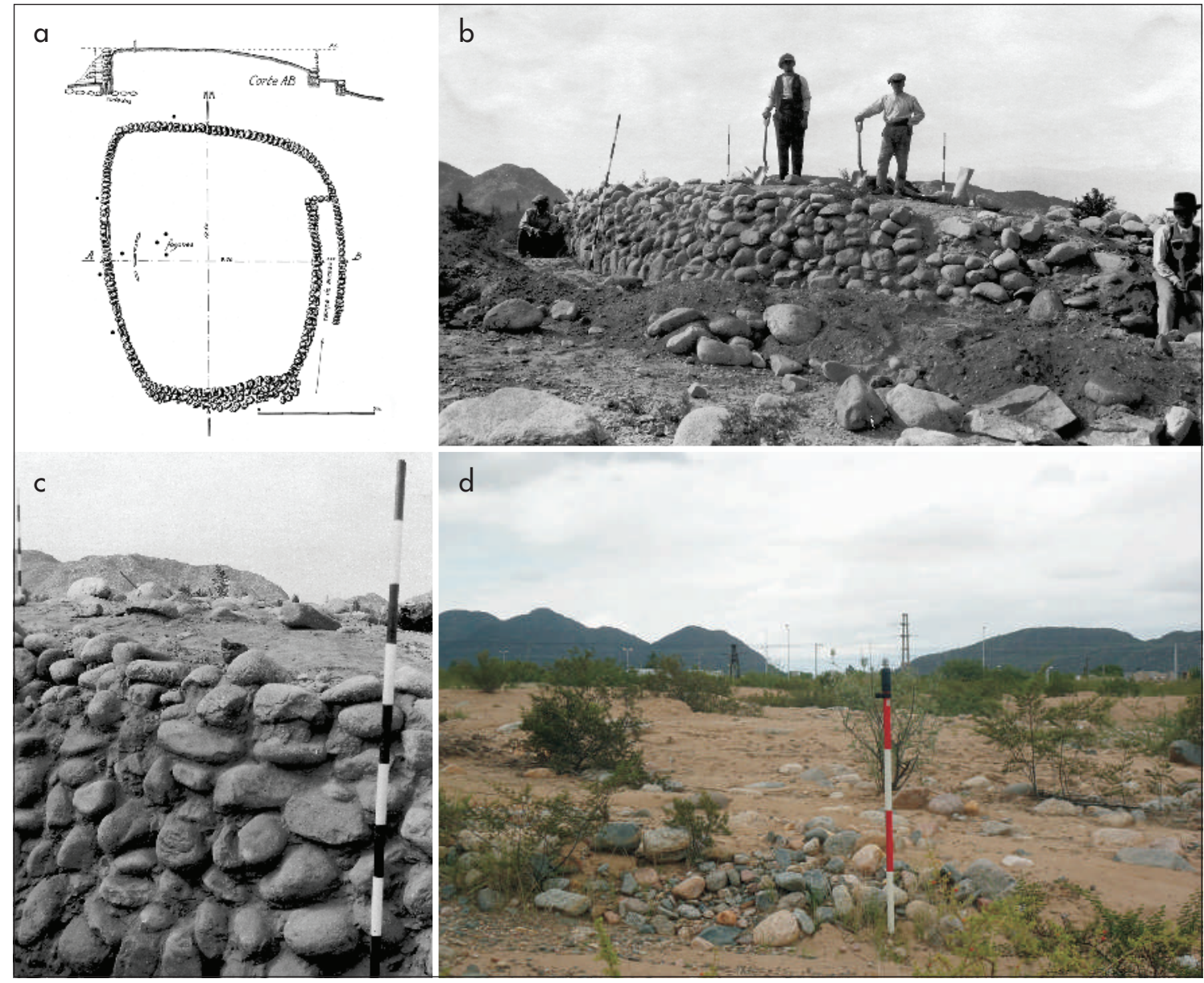

Figura 6: a) plano del sitio El Puquial según Greslebin (1940); b-c) imagen de la plataforma y detalle de sus muros; d) área de la Av. Del Clabecarril donde estuvo emplazado el sitio, hoy totalmente desaparecido. Figure 6: a) plan of El Puquial site according to Greslebin (1940); $\boldsymbol{b}$-c) image of the platform and detail of its walls; $\boldsymbol{d}$ ) area of Av. Del Clabecarril where the site, now completely disappeared, was located.

sentido, podemos destacar el hallazgo de plataformas ceremoniales, no solamente ubicadas en las cumbres, sino a lo largo del territorio que comprenden los trayectos de caminos rituales hacia las áreas donde se realizaban prácticas religiosas (ver Vitry 2007: 77; Bauer 2011: 44; Pino \& Montalván 2014: 82), que también figuran en los escritos de las crónicas referidas: "Hay otra guaca general en los caminos reales y en las plazas de los pueblos, que llaman uznos" (Albornoz [1582] 1967: 24). En el área que nos ocupa dentro de la sierra de Famatina, las plataformas han sido detectadas en los caminos y también en las cumbres de mayor altura.

En el subtramo cuesta del Inca-Pampa de Guacachica, próximo al sitio Las Pircas, registramos a $3539 \mathrm{msnm}$ un espacio de forma aproximadamente cuadrangular de
$26 \times 30$ m ubicada sobe la margen izquierda del camino inka en su ascenso por la ladera occidental. Hacia el este presenta una pared continua con muro doble próximo al ramal del Qhapaq Ñan. Hacia el oeste tiene como límite un filo abrupto igual que hacia el sur, donde se encuentra su mayor elevación. Aquí, sobre el borde, unas curiosas formaciones naturales de rocas emergen del terreno. Detectamos además cuatro alineaciones de rocas que permiten nivelar la pendiente, aterrazar o bien servir como acceso y utilizar el menor esfuerzo para acceder al área más alta del sitio. En este sector y también en la cara norte detectamos fragmentos cerámicos en superficie.

En la estructura descripta se aprovechó un espacio natural sobreelevado respecto al resto del paisaje, que 

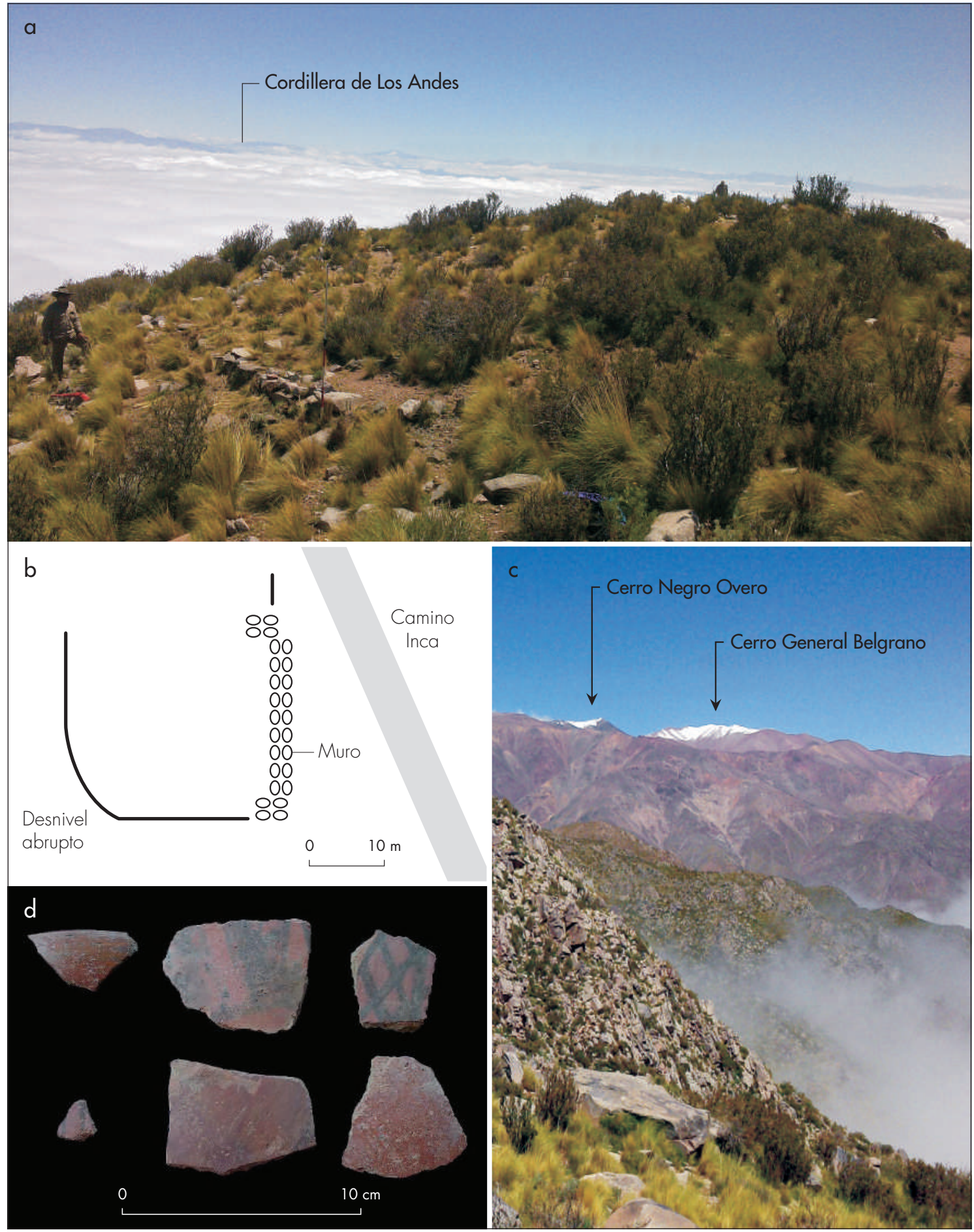

Figura 7: a) imagen de la plataforma cuesta del Inca (3539 msnm); b) croquis de la estructura; c) la plataforma es el último espacio desde donde se puede visualizar las cumbres del Famatina antes del cruce hacia la ladera oriental; d) fragmentos de cerámica inka provincial recolectada sobre la superficie de la plataforma. Figure 7: a) Image of the cuesta del Inca platform (elev. 3539 masl); $b$ ) sketch of the structure; $c$ ) the platform is the last point from which the summits of the Famatina mountains are visible before crossing to the eastern slope; d) fragments of provincial inka pottery, collected on the surface of the platform. 


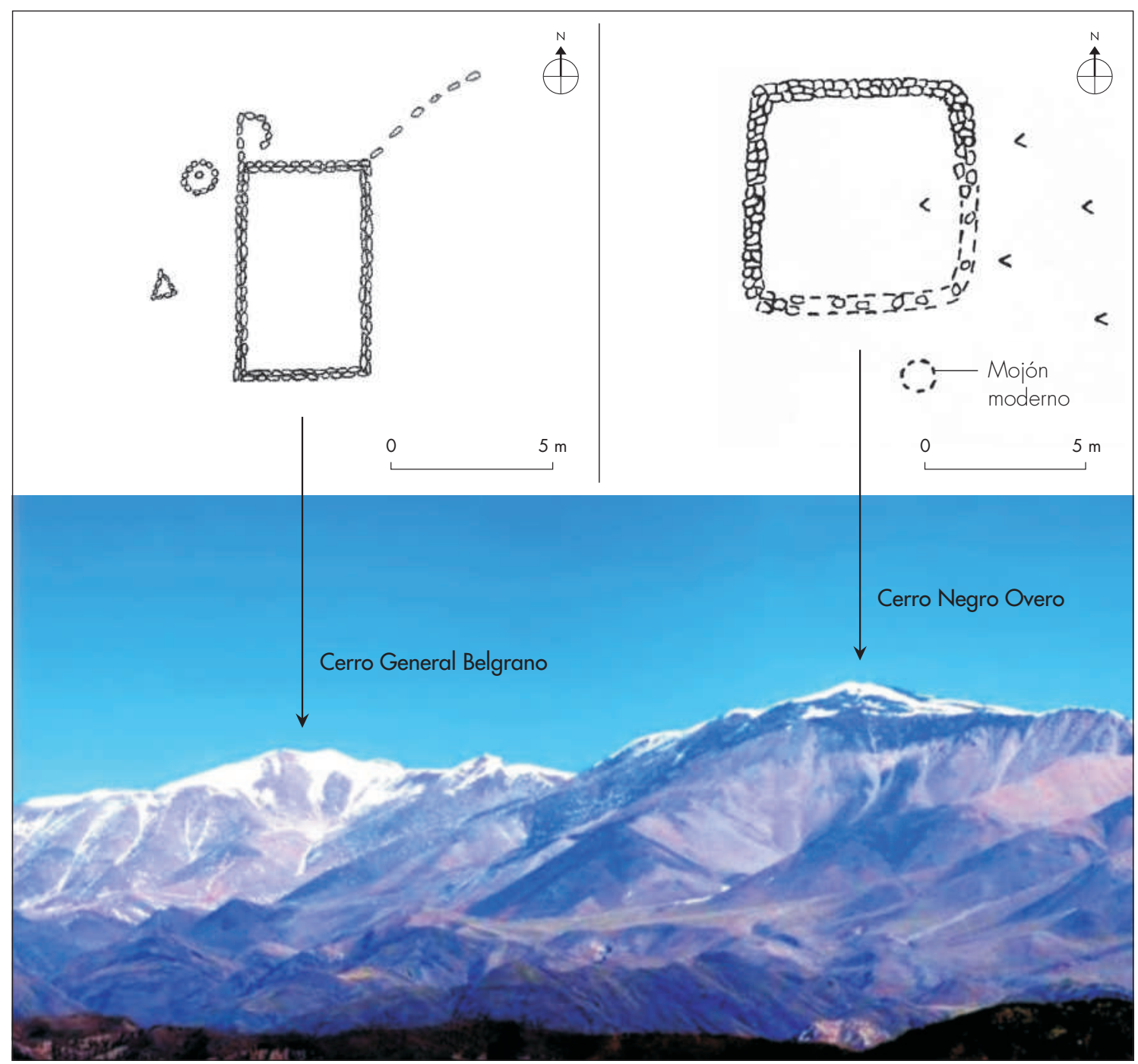

Figura 8. Área de emplazamiento de rectángulos y plataformas ceremoniales de piedra en las alturas de los nevados del Famatina. Vista desde la ladera oriental (planos redibujados de Ceruti 2010 y Schobinger 1966, respectivamente). Figure 8. Area of ceremonial stone platforms and rectangles in the snow-capped heights of Famatina. View from the eastern slope (plans from Ceruti 2010 and Schobinger 1966, respectively).

tenía la particularidad de ser el último lugar desde donde se puede tener acceso visual directo hacia las dos cumbres del Famatina, antes de su derrotero al oriente, y desde donde además se pueden observar las cumbres con santuarios inkas (Ceruti 2004) en la cordillera riojana (fig. 7).

En el mismo sentido, debemos destacar para las zonas de altura detectadas en las dos cumbres más elevadas de los cerros General Belgrano (6097 msnm) y Negro Overo (5791 msnm), la presencia de dos rectángulos ceremoniales (fig. 8) y ofrendas de astas de venado que han sido interpretados como escenarios de posibles rituales de capacochas (Schobinger 1966; Ceruti 2001, 2004, 2007). Estas estructuras arquitectónicas han sido elementos con una fuerte presencia hacia el plano inmaterial y religioso de esta región, al igual que en otros sectores de los Andes. Los sitios han sido considerados como adoratorios o santuarios de altura de filiación inka, donde se realizaron ceremonias y probables peregrinajes en épocas de festividades rituales (ver Ceruti 2004, 2007). 


\section{DISCUSIÓN Y CONCLUSIÓN}

Cuando los españoles invaden el área andina, existían wak'as en muchos espacios de los Andes. También había lugares o u objetos con diversos tamaños y jerarquías que intreractuaban con los habitantes del territorio en la práctica de sus cultos regionales (Bauer 20011: 30). Los inkas habían incorporado estas veneraciones ancestrales de los pueblos locales hacia las wak'as y las resignificaban para conseguir resultados exitosos en su política expansiva. Las wakas actuaban como puentes entre lo humano y lo sobrenatural, organizando los aspectos religiosos e impartiendo nuevos ordenes sociales entre las poblaciones que las frecuentaban (Sánchez Garrafa 2006). El tránsito hacia estos sacros espacios geográficos fue uno de los tantos fines u objetivos del Qhapaq Ñan, al igual que los vínculos con sitios ubicados en entornos estratégicos y convenientes a sus intereses expansionistas. En el caso analizado de la Sierra de Famatina, todos los elementos constitutivos del paisaje arqueológico regional integraban un sistema ceremonial que estaba materializado en el espacio y en sus recorridos. Ejemplo de esto son el ushnu del sitio Tambería del Inca, las plataformas ubicadas en los caminos y sitios, los rectángulos ceremoniales ubicados en las cumbres más altas de la región, las trazas duales de sus rutas, las wankas y los mojones relacionados a la red vial. Tal como se ha detectado para otras regiones del área andina, estas materialidades junto al Qhapaq Nan formaban parte de una cartografía ritual (Pino \& Montalván 2014: 84), constituida por estructuras que cumplían una importante función simbólica de apropiación y resignificación de los paisajes.

Su geografía, atravesada por caminos cargados de sacralidad, cumplieron las premisas de las tradiciones andinas preincas, pero también sirvieron para legitimar los nuevos territorios que el imperio dominaba (Acuto 1999; Bauer \& Stanish 2001).

Probablemente las veneraciones ancestrales hacia las deidades de esta formación riojana habrían estado ligadas al rol de wak'a regional, materializada por estas estructuras (plataformas, rectángulos y ushnu) que en tiempos del inka cumplieron una función religiosa con probables eventos de movimientos de personas (peregrinajes) hacia sus cumbres (Schobinger 1966; Ceruti 2007, 2010; Martin 2015b).

El sistema del Famatina por su relieve y estratégica ubicación puede haber ocupado un lugar de relevancia en el contexto incaico provincial, que excede la función eminentemente material o sesgada hacia lo económico. La visión de las crónicas sobre el aprovechamiento minero de Famatina no ha presentado evidencias arqueológicas directas y las explicaciones funcionales tienden a quedar inmersas en una suerte de reduccionismo que limitan las interpretaciones sobre las causas de dominación del imperio sobre las poblaciones locales. El espacio, cuando es utilizado como recurso, no satisface solamente las necesidades más elementales de supervivencia; poseerlo es sinónimo de riquezas, prestigio y poder (Tuan 1976).

Siguiendo la idea que las wak'as inkas son resignificaciones de las poblaciones locales, intentamos con el Qhapaq Ñan de Famatina realizar la apertura hacia un plano más abarcativo y no menos complejo del pasado regional. El reposicionamiento del ushnu de la Tambería del Inca sobre la plataforma del Puquial puede ser visto como un acto de dominación cultural (Nielsen \& Walker 1999), un mecanismo de control que por intermedio de la conquista ritual ordenó simbólicamente el territorio de la Sierra de Famatina en el proceso de anexión al Tawantinsuyo (Cruz 2009: 71).

La visual hacia los ámbitos sacralizados resultó ser una variable significativa entre las estructuras materiales y los movimientos que realizaron las personas en los distintos paisajes y han presentado su contraparte en algunas crónicas cuando se advierte que desde el camino se construían sitios con funciones sagradas: "todas las veces que veían el cerro le iban mochando...cuando iban desde sus pueblos a Potosí, desde donde le daban la primera vista le mochaban y le llamaban señor, y pedían ventura, salud y riqueza" (Álvarez 1998 [1588]: 347). La orientación del Ushnu de Tambería del Inca, probablemente la del sitio El Puquial, si nos basamos en los planos de Greslebin (1940), y la plataforma relevada en Cuesta del Inca (ladera occidental de la sierra de Famatina) presentarían visuales directas relacionadas a la wak'a de Famatina.

En definitiva, esta serranía podría estar representando un paisaje estatalmente modificado que incorpora una secuencia de espacios sagrados hasta alcanzar el lugar de mayor relevancia (Bauer 2011: 40), en este caso emplazado en las plataformas ceremoniales erigidas en sus cumbres.

Es complejo esgrimir ideas respecto a la invisibilidad del registro minero inka cuando se desarrollan todavía actividades de investigación intensivas en el área. Quizás un marco cronológico más detallado del incario en la región pueda clarificar en este sentido, 
aunque no habría que descartar otras explicaciones sobre la "no presencia" respecto a la minería imperial que, aun sin correlatos materiales, pueden ser igualmente valederas; por ejemplo, las menciones de ciertas wak'as que no fueron trabajadas por el inka ya que habían tenido destinos especiales como la consagración al sol (Platt et al. 2011:153).

Con la complementación de los exiguos datos etnohistóricos y el registro arqueológico en esta área, la wak'a del Famatina podría considerarse otro de los espacios de posible control ideológico inka para la región, utilizando la política sagrada para la dominación de las comunidades locales (Scott 2011:31-32). En igual sentido, las evidencias del registro caminero demostrarían una importante inversión de energía a favor de una estrategia religiosa que seguramente le aportó beneficios al proceso de unificación de sus extensos dominios. Ello se puede deducir de los resultados de aproximaciones holistas a los estudios de la vialidad regional y caminos rituales, demostrando indicadores de sacralización en los segmentos de las áreas ceremoniales de altura (Ceruti 2010), aunque también en el registro vial de las áreas de menor altitud (Martin 2015a, 2015b), exhibiendo evidencias que podrían sustentar la hipótesis de un lugar que ejerció un poder trascendental como waka, incluso de alcance interregional. ${ }^{5}$ Probablemente, esta sacralización del sitio le sirvió al inka para sostener y reforzar vínculos sociales y rituales con las poblaciones locales, y fortalecer y continuar así su avance hacia regiones más meridionales.

Para finalizar, realizaré una breve consideración etimológica respecto al nombre de la serranía que consideramos una wak’a sagrada. Según Dardo de la Vega Díaz en su volumen sobre la toponimia riojana, Famatina podría descomponerse en $f=h u a$, es decir, fama por huama o wama; que podría tener el sentido del que procrea (Díaz 1994).

El término wama ha sido analizado recurrentemente por numerosos autores en la historia de las investigaciones andinas, aunque seguimos las últimas interpretaciones de Pino (2016) que desde los registros etnográficos asegura que:

el concepto de Wamani no es directa ni equivalente al término "provincia", sino más bien la idea de Wamani está íntimamente vinculada a la autoridad y el ejercicio de poder de un líder que representa en vida a un ancestro y a la territorialidad que este ejerce con su grupo social sobre un espacio o conjunto de espacios, considerados como territorios de estos grupos sociales que se encuentran vinculados, identificados y emparentados con un aspecto geográfico significativo (montañas, cuevas, lagunas y manantiales) que representa el lugar de origen y residencia de sus ancestros en común, es decir, cada uno de estos espacios geográficos y su entorno vendrían a ser paisajes sacralizados que poseen Waman o donde reside el Waman (Pino 2016: 171).

La terminación tin o tim para Lafone Quevedo representa la idea de junta o reunión, basándose en la voz tincu de la que se extrae una raíz tin (Díaz 1994). Así, el termino wamatin, wamatinae $\mathrm{o}$ wamatinag podría direccionarse etimológicamente hacia posibles evidencias como ámbito ritual de encuentros o reuniones con los ancestros sagrados que arqueológicamente estarían señalados por los caminos hacia los adoratorios de altura y los ushnus, plataformas y sitios menores con visuales directas hacia los ámbitos religiosos (Pino 2016: 172).

La fusión de los elementos que componen la materialidad del Qhapaq Ñan han dotado al paisaje de componentes rituales que colaboran en la sacralización del territorio y le asignan características que lo distinguen del resto de la región, quizás por ser esta la serranía de mayor altitud (fuera del sistema cordillerano) y ubicada más al este del Kollasuyu meridional.

\section{NOTAS}

${ }^{1}$ Una de las definiciones más generales sobre los ushnus no duda en asignar a estas estructuras una función eminentemente ritual y simbólica, pudiendo estar representados por un espacio, un lugar, una roca o simplemente estructuras en la que se desarrollaron rituales colectivos y públicos, especialmente de libaciones u ofrendas (Pino 2010: 88).

${ }^{2}$ A fines de 2015 comenzamos un proyecto desde el CIAP-INAPL que incluye, entre otros objetivos, una actualización planimétrica del sitio con el uso de GPS geodésico. Los resultados están aún en procesamiento.

${ }^{3}$ Siguiendo a Winchkler (2006), entendemos por conanas a aquellos instrumentos pasivos usados para moler diversos productos, con una cavidad más larga que ancha generada por los efectos de desgaste de un instrumento activo con movimientos horizontales.

${ }^{4}$ A comienzos de 2015, intentamos identificar el área de emplazamiento del sitio que, por estar ubicado en pleno casco urbano a unos $1.500 \mathrm{~m}$ de la Plaza principal de Chilecito, ha desaparecido merced a la construcción del cablecarril y de las avenidas que ascienden siguiendo este patrimonio histórico.

${ }^{5}$ Por interregional me refiero al menos a los dos valles: Famatina y Antinaco - Los Colorados al este y Valle del Bermejo al oeste. 
RECONOCIMIENTOS A Diana Rolandi (INAPL). A todos los participantes de campañas, en diferentes momentos de la historia del proyecto. Al Dr. Pedro Salminci ${ }^{\dagger}$ con quien realizamos parte de los relevamientos de tambería del Inca en diciembre de 2015. A Mercedes Maison y Gimena Conforti del área de geomática del INAPL por su colaboración con los mapas del proyecto. A las autoridades de la Secretaria de Cultura: Víctor Robledo, Verónica Vargas y Laura Gachón. Al Ministerio de Cultura de la Nación Argentina por sus aportes económicos para la investigación. Al Coordinador general del Taller Qhapaq Nan I y a los editores responsables de esta publicación.

\section{REFERENCIAS}

Acuto, F., 1999. Paisaje y dominación. La constitución del espacio social en el Imperio Inka. En Sed non satiata. Teoría social en la arqueología latinoamericana contemporánea, A. Zarankin \& F. Acuto, Eds., pp. 33-75. Buenos Aires: Ediciones del Tridente.

Albornoz, C., 1967 [1582]. La instrucción para descubrir todas las huacas del Pirú y sus camayos haciendas. Journal de la Société des Américanistes 56: 7-39. París.

Álvarez, B., 1998 [1588]. De las costumbres y conversión de los indios del Perú. M. Martín, J. Villarías \& F. del Pino, Comps. Madrid: Polifermo Ediciones.

Aparicio, F. De, 1936. La tambería de Los Cazaderos. Relaciones de la Sociedad Argentina de Antropología 1: 77-88. Buenos Aires.

BÁrCenA, R., 1989. Pigmentos en el ritual funerario de la momia del cerro Aconcagua (Provincia de Mendoza, República Argentina). Xama 2: 61-116. Mendoza.

BÁrCEnA, R. \& S. MARTin, 2009. Modelos complementarios de la red vial inka en La Rioja. Nuevos aportes para la dominación incaica del centro oeste argentino. En Problemáticas de la arqueología contemporánea, A. Austral \& M. Tamagnini, Comps., Tomo III, pp. 83-90. Córdoba: Universidad Nacional de Río Cuarto.

Bauer, B. \& C. StAnish, 2001. Ritual and pilgrimage in the ancient Andes. Austin: University of Texas Press.

BAuer, B., 2011. Estudio arqueológico sobre los Incas. Cuzco: Centro Bartolomé de Las Casas.

BAzÁn, A., 1979. Historia de La Rioja. Buenos Aires: Plus Ultra.

BECERRIL, A., 2012. Las montañas humanizadas: los volcanes del altiplano central. Kinkaban 1 (1): 64-70. Ciudad de México.

Boman, E., 1920. Vorspanische Whonsttäten, Steinwerkstätte und Petroglyphen in der Sierra de Famatina. Zeitschrift des Deutschen Wissenschaftlichen Vereins zur Kultur-und Landeskunde Argentiniens 6: 25-39. Buenos Aires.

BRodA, J., 1996. Paisajes rituales en el altiplano central. En Arqueología Mexicana, Volumen Iv, pp. 40-49. México: Raíces.

Carrizo, J., 1942. Cancionero popular de La Rioja. Buenos Aires: Universidad Nacional de Tucumán.
Cavero, Y., 2010. Inkapamisan. Ushnu y santuario inca en Ayacucho. Ayacucho: Edición del Autor.

Ceruti, C., 2001. La sacralidad de las montañas en el mundo andino. En El santuario incaico del cerro Aconcagua, J. Schobinger, Comp., pp. 379-394. Mendoza: Universidad Nacional de Cuyo.

Ceruti, C., 2004. Arqueología de alta montaña en La Rioja. Salta: Universidad Católica de Salta.

Ceruti, C., 2007. Nuevos avances en la prospección arqueológica del Famatina. En Actas del XVI Congreso Nacional de Arqueología Argentina, Tomo III, pp. 515-520. Jujuy: Universidad Nacional de Jujuy.

Ceruti, C., 2010. Arqueología en la sierra más alta del mundo: santuarios incaicos en el cerro Negro Overo y cumbre General Belgrano de los nevados de Famatina (La Rioja, Argentina). Inka Llaqta 1: 225-243. Lima.

Claval, P., 1999. La geografía cultural. Buenos Aires: Eudeba.

Cruz, P., 2009. Huacas olvidadas y cerros santos. Apuntes metodológicos sobre la cartografía sagrada en los Andes del sur de Bolivia. Estudios Atacameños 38: 55-74.

D’altroy, T., 2003. Los Incas. Barcelona: Ariel.

De la Fuente, E., 1969. La fundación de La Rioja. En Manual de Historia y Geografía de La Rioja. Tomo 1, pp. 11-69 La Rioja: Compañía Editora Riojana.

De la fuente, E., 1977. La tambería del Inca. La Rioja: Edición del autor.

De la fuente, N., 1971. Las culturas prehispánicas de la provincia de La Rioja. Panorama general. Córdoba: Museo Arqueológico Regional Aníbal Montes.

Debenedetti, S., 1917. Los yacimientos arqueológicos occidentales del Valle de Famatina (Provincia de La Rioja). Revista de la Sociedad Argentina de Ciencias Naturales PHYSIs, Tomo III: 386-404. Buenos Aires.

FARRINGTON, I., 1992. Ritual geography, settement patterns and characterization of the provinces of the inka heartland. World Archaeology 23 (3): 368-385. Londres.

FARrington, I., 2016 Ms. The centre of the world and the inka concept of ushnu.

GonzÁlez, A., 1982. Las provincias incas del antiguo Tucumán. Revista del Museo Nacional de Lima. 46: 317-380. Lima.

Greslebin, H., 1940 Ms. Investigaciones arqueológicas en la Tambería del Inca. Chilecito. La Rioja. Buenos Aires.

Hyslop, J., 1992. Qhapaqñan. El sistema vial incaico. Lima: Instituto Andino de Estudios Arqueológicos.

Jасов, C. \& I. Leibowicz, 2011. Montañas sagradas en los confines imperiales. Nevado de Cachi, Salta. Argentina. Haucaypata 2: 71-90. Lima.

Jofré, G., 2015. Más allá y más arriba del Cuzco. En torno a los ushnus de puna durante el Horizonte Tardío. Haucaypata 9: 6-20. Lima.

KüHN, F., 1919. Observaciones morfológicas en la región central de la sierra de Famatina. En Anales del Museo de Historia Natural 30, pp. 255-280. Buenos Aires. 
LeVILlier, R., 1920. Papeles de los gobernadores en el siglo XVI. Madrid: Imprenta J. Pueyo.

Levillier, R., 1926. Nueva crónica de la conquista del Tucumán. Tomo II. Buenos Aires: Nosotros.

Lozano, P., 1874. Historia de la conquista del Paraguay, Río de la Plata y Tucumán. Tomo Iv. Buenos Aires: Lamas.

Lynch, J., M. Giovannetti \& M. PÁEZ, 2010. Ushnus de las provincias del sur del Tawantinsuyu. Comparación entre las estructuras de los sitios El Shincal y Hualfín Inka en el centro de Catamarca (Argentina). Revista de Arqueología Americana 28: 49-81.

MARTin, S., 2001. Explotaciones mineras y registro espacial inka en la Sierra de Famatina. En Actas del XIII Congreso Nacional de Arqueología Argentina. Tomo 1, pp. 347-360. Universidad Nacional de Córdoba.

Martin, S., 2004. Breve Historia de la minería precolombina. En Historia de la minería argentina, Tomo I: 299-310. Buenos Aires: Servicio Geológico Minero Argentino, Secretaría de Industria, Comercio y Minería, Ministerio de Economía de la Nación Argentina .

Martin, S., 2005. Caminos incaicos principales y secundarios en la Sa. de Famatina. La Rioja-Argentina. Actualización y revisión conceptual. Xama 15-18: 21-35. Mendoza.

Martin, S., 2015a. Rocas del Qhapaq Nan: wankas y mojones en los caminos duales a las cumbres sagradas de la Sierra de Famatina (La Rioja-Argentina). Haucaypata. Investigaciones arqueológicas del Tahuantinsuyo 10: 78-97. Lima.

Martin, S., 2015b. Caminos dobles del Kollasuyu: dualidad y peregrinajes en el Qhapaq Nan de la Sierra de Famatina (La Rioja-Argentina). Revista de Antropología del Museo de Entre Ríos 1 (1): 44-54. Entre Ríos.

Matienzo, J., 1910 [1567]. Gobierno del Perú. Buenos Aires: Compañía Sudamericana de Billetes de Banco.

Matos, R., 1994. Pumpu, centro administrativo de la Puna de Junín. Lima: Horizonte.

Meddens, F.; C. McEwan \& C. Vivanco Pomacanchari, 2010. Inca "stone ancestor" in context at a high-altitude ushnu platform. Latin American Antiquity 21 (2): 173-194.

Meddens, F., 1997. Function and meaning of the ushnu in Late Horizon Perú. Tawantinsuyu 3: 4-14. Camberra.

Monteverde, R., 2011. Los incas y la fiesta de la situa. Chungará 43 (2): 243-256. Arica.

Nielsen, A. \& W. WAlKer, 1999. Conquista ritual y dominación política en el Tawantinsuyu: el caso de Los Amarillos (Jujuy, Argentina). En Sed non satiata. Teoría social en la arqueología latinoamericana, A. Zarankin \& F. Acuto, Eds., pp. 153-169. Buenos Aires: Ediciones del Tridente.

OвERTI, I., 1997. Investigaciones preliminares en Usno-Moq'o, Abancay. Tawantinsuyu 3: 15-21. Camberra.

PIno, J., 2004. Observatorios y alineamientos astronómicos en el Tampu Inka de Huanuco Pampa, Perú. Arqueología y Sociedad 15: 173-190. Lima.

Pino, J., 2010a. Yllapa Usno: rituales de libación, cultos a ancestros y la idea del ushnu en los Andes según los documentos coloniales del siglo XVI-XVII. Arqueología y Sociedad 21: 77-108. Lima.

Pino, J., 2010b. El ushnu inca de Huánuco Pampa: organización espacial, arquitectura y uso ceremonial. Tesis para obtener el grado de Magíster en Arqueología con mención en Estudios Andinos. Escuela de Posgrado, Programa de Estudios Andinos, Pontificia Universidad Católica del Perú. Lima.

PINo, J., 2016. Qhapaq Nan Wamanin: los lugares de libación como hitos de la memoria en cada paisaje sagrado de la ruta principal hacia el chinchaysuyu. Diálogo Andino 49: 167-180. Arica.

Pino, J. \& W. Montalván, 2014. El ushnu, el qhapaq ñan y las huacas en el altiplano del chinchaycocha. Una aproximación a las estrategias de apropiación y control territorial inca desde la lectura de los paisajes rituales y la astronomía. Haucaypata 4 (8): 64-90. Lima.

Platt, T., T. Bouysse-CASAgne \& O. Harris, 2011. QaraqaraCharka. Mallku, Inka y Rey en la provincia de Charcas (siglos XV-XVII). La Paz: Instituto Francés de Estudios Andinos-Plural Editores-University of St. AndrewsUniversity of London.

RAFFino, R., 1982. Los Inkas del Kollasuyu. Origen, naturaleza y transfiguraciones de la ocupación inka en los Andes meridionales. Buenos Aires: Ramos Americana.

RAFFiNo, R., 1996. Inka road research and Almagro's route between Argentina and Chile. Tawantinsuyu 1: 36-45. Camberra.

Raffino, R.; D. Gobbo, R. Vázquez, A. Capparelli, V. Montes, D. Iturriza, C. Deschamps \& M. Mannasero, 1997. El ushnu de El Shincal de Quimivil. Tawantinsuyu 3: 22-39. Camberra.

Reinhard, J., 2012. Las montañas Sagradas y las culturas preincaicas de los Andes. En América: tierras de montañas y volcanes. Huellas de la Arqueología, M. Chávez, S. Ianiszewski \& R. Cabrera, Eds. México, D.F.: Instituto Nacional de Antropología e Historia.

Rhomeder, G., 1949. Estudio de un prehispánico camino de cuesta por la Sierra de Famatina. Revista del Instituto de Antropología 4: 84-93. San Miguel de Tucumán.

Robledo, V., 2007. La Rioja indígena. Origen, conquista y persistencia. La Rioja: Nexo Ediciones.

Rostworowski, M., 2003. Peregrinaciones y procesiones rituales en los Andes. Journal de la Société des Américanistes 89 (2): 97-123.

Rostworowski, M., 2004. La influencia Wari en el incario y las peregrinaciones. Boletín de Arqueología PUCP 8: 23-30. Lima.

Sallnow, M., 1987. Pilgrims of the Andes. Regional cults in Cusco. Washington, D.C.: Smithsonian Institution Press.

SÁncheZ, R., 2006. Apu de los cuatro suyos: construcción del mundo en los ciclos mitológicos de las deidades montaña. Tesis para optar el grado de Doctor en Ciencias SocialesEspecialidad en Antropología. Facultad de Ciencias Sociales, Universidad Nacional Mayor de San Marcos. Lima. 
Sanhueza, C., 2011. Atacama y Lípez. Breve historia de una ruta: escenarios históricos, estrategias indígenas y ritualidad andina. En En Ruta. Arqueología, historia y etnografía del tráfico sur andino. L. Núñez \& A. Nielsen, Eds., pp. 313340. Córdoba: Encuentro Grupo Editor-Editorial Brujas. Schobinger, J., 1966. Arqueología de alta montaña. En Anales de Arqueología y Etnología, Tomo xxI, pp. 139-196. Mendoza: Universidad Nacional de Cuyo.

Scotт, A., 2011. Sacred politics. An examination of Inca huacas and their use for political and social organization. En Totem. The University of Western Ontario Journal of Anthropology, Volumen 17, pp. 23-36. <http://ir.lib.uwo. $\mathrm{ca} /$ cgi/viewcontent.cgi $?$ article $=1203 \&$ context $=$ totem $>$ [Consultado 23-10-2017].

TARragó, M. \& L. GonzÁLEZ, 2004. Arquitectura social y ceremonial en Yocavil, Catamarca. Relaciones de la Sociedad Argentina de Antropología 29: 297-315. Buenos Aires.

TuAn, Y., 1976. Geografía humanística. Annals of the Association of American Geographers 66 (2): 266-276.

Uhle, M., 1980 (1912). Las relaciones prehistóricas entre el Perú y Argentina. Radiocarbono en Arqueología 1 (4/5): 61-80. Mendoza.
Valderrama, R. \& C. Escalante, 2012. Montañas sagradas y rituales en los Andes. En Cultura andina: cosmovisión, arqueología, J. Rozas \& D. Blanco, Eds., pp. 19-50. Cusco: Universidad San Antonio Abad.

VITRY, C., 2002. Apachetas y mojones, marcadores espaciales del paisaje prehispánico. Revista Escuela de Historia 1 (1): 179-191. Salta.

VITRY, C., 2007. Caminos rituales y montañas sagradas. Estudio de la vialidad Inka en el Nevado de Chañi, Argentina. Boletín del Museo Chileno de Arte Precolombino 12 (2): 69-84. Santiago.

WinchKLeR, G., 2006. Diccionario de uso para la descripción de objetos líticos. $<\mathrm{http}$ ///www.winchkler.com.ar/Diccionario. pdf $>$ [Consultado 23-10-2017].

Zuidema, R., 1980. El ushnu. Revista de la Universidad Complutense 117: 317-362. Madrid.

Zuidema, R., 1995. El sistema de ceques del Cuzco: la organización social de la capital de los incas. Lima: Pontificia Universidad Católica del Perú. 